\title{
ANALYSIS OF THE STATE AND DEVELOPMENT OF AGRICULTURE IN BULGARIA BY STATISTICAL REGIONS AND IN THE DISTRICT OF DOBRICH IN THE CONTEXT OF RESTRUCTURING AND DE- CENTRALIZATION
}

\author{
Krassimira Zagorova ${ }^{1}$
}

DOI: https://doi.org/10.31410/ERAZ.S.P.2019.19

\begin{abstract}
The substantial land ownership changes in the Republic of Bulgaria and the restructuring of the agricultural production structures was the primary goal towards the attainment of balance in the management and regulated usage of land resources as a major and specific means of production. The purpose of the paper is to analyze the state and development of agricultural production in the context of decentralisation and restructuring of land ownership in the agricultural sector in Bulgaria. More precisely, the paper examines the dynamics of the indicators relevant for the relative share of the utilised agricultural area by statistical regions of the country, the structure of agricultural produce grown in different regions, the distribution of the cultivated areas by the types of crops. Further extensive research was carried out not only into the structural portfolio of the cultivated crop production in the district of Dobrich, whose produce takes a leading position in the overall agricultural output of Bulgaria, but also into the cultivated areas by groups of agricultural crops conditional upon the specific climatic and physic-geographical factors of the region.
\end{abstract}

Keywords: Utilised agricultural area, Monocultural production, Agricultural (crop) production, District of Dobrich.

\section{INTRODUCTION}

$\mathrm{T}$ he change in land ownership and the restructuring of the structures of agricultural production was the principal objective for achieving the right balance between the regulated use and management of the land as a fundamental and specific means of production. The slower pace of implementation of the agrarian reform ${ }^{2}$ in Bulgaria has contributed to the delay in the development of the agricultural sector, both at national and regional level.

Forced to work under conditions of high risk, predetermined not only by the seasonality of the production but also by the economic uncertainty in the country, including the shrinking domestic consumption, without access to foreign markets and centralized procurement, with no effective system of financing and genuine investment interest, using obsolete technologies and depreciated farm machinery, the farmers have further increased the „chaos” and widened the domestic market deficit.

The growing problems in the context of decentralised restructuring of the agriculture sector require the adoption of a national strategy for the development of agriculture in Bulgaria, aligned

\footnotetext{
Technical University of Varna, Studentska 1 St., Varna, Bulgaria

Agrarian reform in Bulgaria is associated with the transition from public to private governance and management of agricultural land in accordance with the Agricultural Land Ownership and Use Act adopted in 1991. The transition to private management and ownership of agricultural land is accompanied by the reorganization of state structures operating in the form of labour-cooperative agricultural farms, state farms and agro-industrial complexes and the creation of private agricultural production (farm) units.
} 
and synchronized with the requirements set forth by the existing Agricultural Policy of the European Union (EU), and which, along with a medium-and long-term planning of agricultural production will neutralise or mitigate the adverse processes and effects upon its development. The control and management of the latter through appropriate mechanisms tailored to the specificity of the regions, including the region of the District of Dobrich is of utmost importance for that part of the population for which agricultural production is traditionally the main means of livelihood [4].

\section{STATE AND DEVELOPMENT OF AGRICULTURE IN BULGARIA BY STATISTICAL REGIONS}

\subsection{Use of agricultural area in Bulgaria by regions}

According to data of the Department of Agro-Statistics at the Ministry of Agriculture, Food and Forestry (MAFF) the District of Dobrich has the highest relative share of the utilised agricultural area (UAA) as of $2018-7,3 \%$ of the country's UAA, followed by the District of Pleven with $6,6 \%$ and the district of Plovdiv covering 5,9\% of the total usable agricultural area of the country as a whole (see Figure 1). According to the data from the cited source, the District of Dobrich takes a leading position in terms of the size of the arable agricultural land, which accounts for approximately $10,0 \%$ of the total arable land for the country and is the largest as compared to the other administrative districts of Bulgaria.

According to data of MAFF, as of 2018 the largest percentage of arable agricultural area is concentrated in the North-Western statistical area with a relative land share of 23,3\%, followed by the North-Eastern and North Central region comprising 21,6\% and 19,1\% of the total arable land in the country, respectively.

The districts of Dobrich and Pleven have the largest percentage of arable land, amounting to $9,6 \%$ and $8,7 \%$ of the total cultivable areas of Bulgaria, respectively. This fact confirms the leading position of the District of Dobrich in the agricultural sector of Bulgaria as well as the structure-forming role of agricultural production in the regional economy of the district.

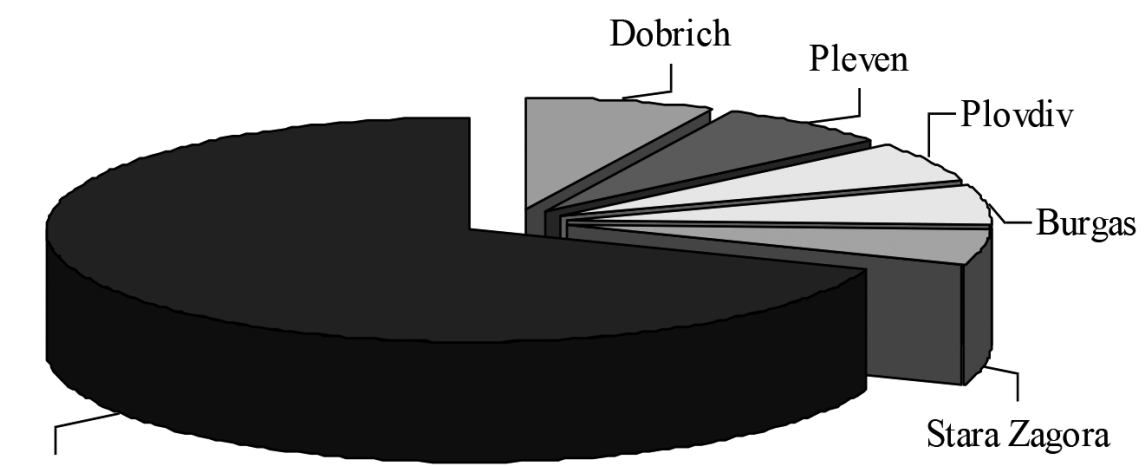

22 districts

$\square$ Dobrich $\square$ Pleven $\square$ Plovdiv $\square$ Burgas $\square$ Stara Zagora $\square 22$ districts

Figure 1: Distribution of the utilised agricultural area in 2017 by administrative districts ${ }^{3}$

\footnotetext{
3 According to the data of the Department of „Agrostatistics” at the MAFF of the Republic of Bulgaria, Bulgarian Survey of the Agricultural and Economic Conjuncture BANCIK, 2018
} 


\subsection{Structural portfolio of the crop production in the district of Dobrich and in Bulgaria by regions}

The development of agriculture in the district of Dobrich is characterized by certain advantages distinguishing it from the other administrative districts in the country that manifest themselves through extremely favourable combination of the region-specific natural and climatic features - i.e. plain flat terrain, good soil structure and ecologically clean natural surroundings -a prerequisite for achieving high productivity and quality levels of the regional crop production, facilities for post-harvest on-site handling of crop output to high-quality end-products oriented primarily toward the domestic market, approximately $100 \%$ of tillage and cultivation of agricultural land and an active land market ${ }^{4}$.

The region's prime conditions for raising crops are also reinforced by the high share of arable land - 332172 ha, which amounts to 70,5\% of the territory of the district with the country's average of $-31,3 \%$ and around $10 \%$ of the country's cultivable crop land.
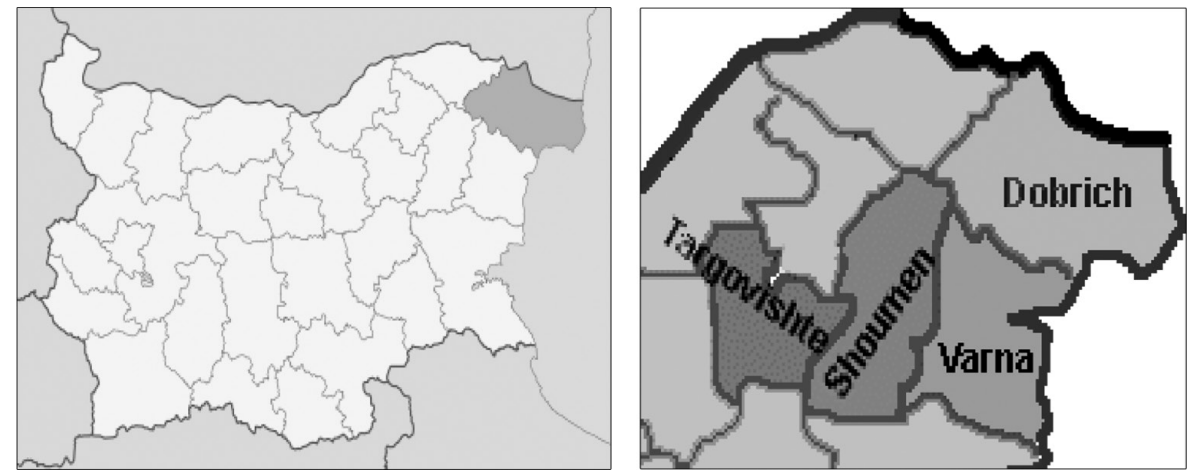

Figure 2: Location of the District of Dobrich within the territory of the Republic of Bulgaria

Despite the district's advantageous physic-geographical factors, the structural portfolio of the cultivated agricultural output in the region focuses mainly on the production of grain or cereal crops, oleaginous and fodder crops - wheat, maize, sunflower, rape and barley. In recent years there has also been a steady trend in increasing the areas being cultivated for the growing of lavender as a kind of essential oil crops, whose amount has been increasing progressively over the period 2014 -2017 from 4461 acre in 2014 to 24658 acres in 2017 [3].

The areas planted with industrial crops have a relatively small share, while those cultivated for perennial plants have the smallest relative share that accounts for $1,2 \%$ of the total usable agricultural area in the region.

Likewise, the areas for production of intensive vegetable crops through irrigation have also been extremely reduced to make up an average of 1,65\% of the region's UAA. This, by all means, is due to the limited surface water sources on the territory of the district and the presence of plentiful but less easily accessible aquifers. The dynamics in the distribution of the cultivated land and UAA for the principal agricultural crop types of the District of Dobrich is provided in Table 1.

$4 \quad$ The District of Dobrich is one of the four districts located in the North-East Planning Region of Bulgaria differentiated according to the Regional Development Act and in line with the requirements of the Common classification of territorial units for statistics implemented in the EU for the purposes of planning, management, resource provision and assessment of their regional development. To the north, the district borders on the Republic of Romania, to the east on the Black sea, to the south on the District of Varna and to the west on the District of Silistra (see Figure 2). 
Table 1. Agricultural areas by groups of agricultural crops in the District of Dobrich, ha

\begin{tabular}{|l|c|c|c|c|c|c|}
\hline \multirow{2}{*}{$\begin{array}{l}\text { Utilised agricultural } \\
\text { area by crops }\end{array}$} & \multicolumn{2}{|c|}{$\mathbf{2 0 1 5}$} & \multicolumn{2}{c|}{$\mathbf{2 0 1 6}$} & \multicolumn{2}{c|}{$\mathbf{2 0 1 7}$} \\
\cline { 2 - 7 } & Area & UAA, $\%$ & Area & UAA, $\%$ & Area & UAA, \% \\
\hline Grain or cereal crops & 212796 & 57,2 & 196527 & 52,5 & 206508 & 56,0 \\
\hline Oleaginous crops & 101137 & 27,2 & 116287 & 31,1 & 106930 & 29,03 \\
\hline Industrial non-oleaginous & 1124 & 0,30 & 3462 & 0,92 & 5004 & 1,36 \\
\hline Vegetables and flowers & 5619 & 1,51 & 6619 & 1,76 & 8069 & 2,19 \\
\hline perennial plants & 4291 & 1,15 & 3869 & 1,03 & 3727 & 1,01 \\
\hline UAA in Dobrich District & \multicolumn{2}{|c|}{372368 ha } & \multicolumn{2}{|c|}{369421 ha } & \multicolumn{2}{c|}{368282 ha } \\
\hline
\end{tabular}

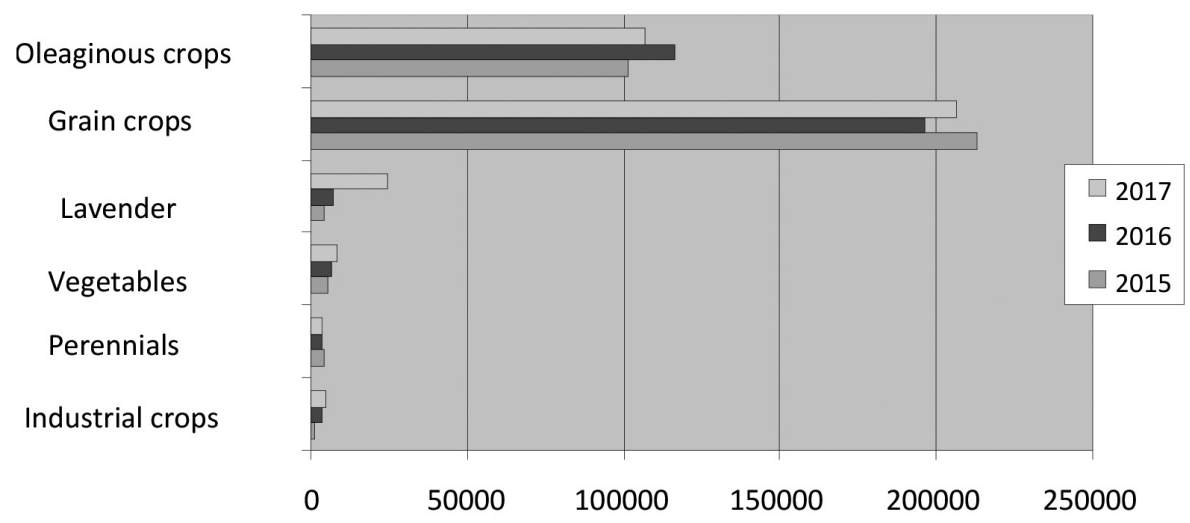

Figure 4: Distribution of the utilised agricultural crop area in the District of Dobrich ${ }^{5}$

The data provided for the distribution of utilised agricultural crop areas in the District of Dobrich highlight the particular disposition of the farmers in the region towards a more monocultural (unvaried) production which has some advantages, but also poses serious risks.

Monocultural production often disrupts the natural cycle of crop rotation and, consequently, results in deteriorated land productivity. There is also the additional risk of crop destruction caused by natural disasters in conditions of dynamic climate changes and underdeveloped crop insurance culture for the vast majority of farmers, incl. the tenants of large-scale agricultural land. The narrowly specialized production of a limited type of agricultural crops grown in other regions of the country will be unprofitable in view of the existing risk and increased overproduction.

The production of grain - fodder and oleaginous crops in large specialized farms across the District of Dobrich presupposes improved productivity levels and yields above the country's average, although, against the performance results of the countries with well-developed agricultural farms, the latter are significantly lagging behind. Large-scale cultivation of extensive crops is a long-established practice both across the entire country and on the territory of the district itself and is also encouraged and sustained by the equal direct payment scheme per unit of agricultural area provided through European Agricultural Fund.

The small size of the intensive agricultural crop areas determines the extremely restricted and insufficient amount of financial subsidies to support the farms in which they are grown. Under such circumstances, the production of intensive agricultural crops including fresh fruit and vegetables has been drastically curtailed, regardless of their increased demand, both domestically and internationally.

5 Source: Territorial units for statistics Dobrich; Department of “Agrostatistics”, MAFF, 2015, 2016, 2017 
Grown in the District of Dobrich, for the needs of the local market, are certain types of intensive agricultural crops - mostly vegetables and orchards, as well as irrigated maize, the production of which is located in the lands of the municipalities of Kavarna, Shabla and, to some extent, in the municipalities of Balchik and Dobrich rural municipality. On the territory of the afore-mentioned municipalities the largest share of intensive agricultural crop areas relates to the growing of vegetables: pepper, bell-pepper, auberge, cabbage, potatoes, tomatoes, peas and others.

Cultivated in the lands of the municipalities Dobrichka - rural and Balchik are also farm orchard trees such as apples, peaches, apricots, walnuts.

Despite the scarcity of surface water sources on the territory of the district of Dobrich, experts claim that the lands of the municipalities of Shabla, Kavarna and Balchik, offer exceptional opportunities for irrigation, as regards the existence of «rich» aquifer horizons, which in the reconstruction of the fully operable irrigation systems, mainly on the territory of the abovenamed municipalities, would secure the region with irrigation water at a reasonable price.

As of 2017, the largest share of the cultivated areas in the surveyed region pertains to cereal and oleaginous crops, with the most widespread produce being that of wheat, maize and sunflower. It is for these crops precisely that the District of Dobrich takes a leading position in the country as compared to the other regions of Bulgaria with highly developed production of extensive agricultural crops.

Illustrated in Table 2, Figure 5, 6 and 7 [6] is the relative share and the size of the areas utilized for the growing of basic cereal and oleaginous crops in the country as of 2017 by statistical districts.

Table 2. Areas utilized for the growing of basic cereals and oleaginous crops, 2017.

\begin{tabular}{|c|c|c|c|}
\hline Utilised agricultural crop areas, ha & $\begin{array}{c}\text { Utilised area for } \\
\text { Bulgaria }\end{array}$ & \multicolumn{2}{|c|}{ Utilised area - Dobrich District } \\
\cline { 3 - 4 } & Utilised area, ha & $\begin{array}{c}\text { \% of area under cul- } \\
\text { tivation }\end{array}$ \\
\hline $\begin{array}{c}\text { Grain or cereal crops } \\
\text { (wheat, barley, maize) }\end{array}$ & 1866944 & 206508 & 62,1 \\
\hline $\begin{array}{c}\text { Oleaginous crops } \\
\text { (sunflower, rape) }\end{array}$ & 106930 & 86486 & 35,1 \\
\hline
\end{tabular}

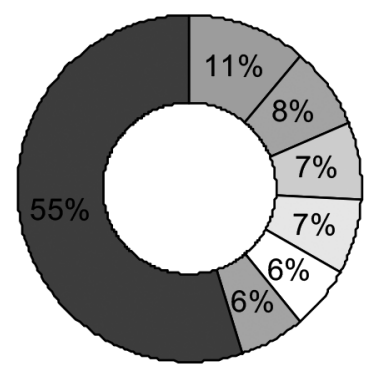

$$
\square \text { Dobrich }
$$

$\square$ Silis tra
22 dis trict $\square$ Pleven

$\square$ Stara Zagora $\square$ Russe

$\square$ Vracha

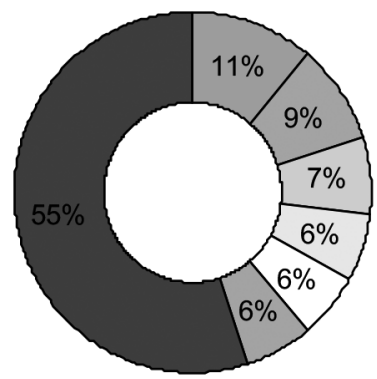

\begin{tabular}{|c|c|c|c|}
\hline$\square$ Dobrich & $\square$ Pleven & $\square$ Plovdiv & $\square$ Russe \\
\hline$\square$ Yambol & $\square \mathrm{V}$, Tarnovo & $\square 22$ districts & \\
\hline
\end{tabular}

Figure 5: Structure of maize and wheat cultivated areas in the country by districts, 2017. 


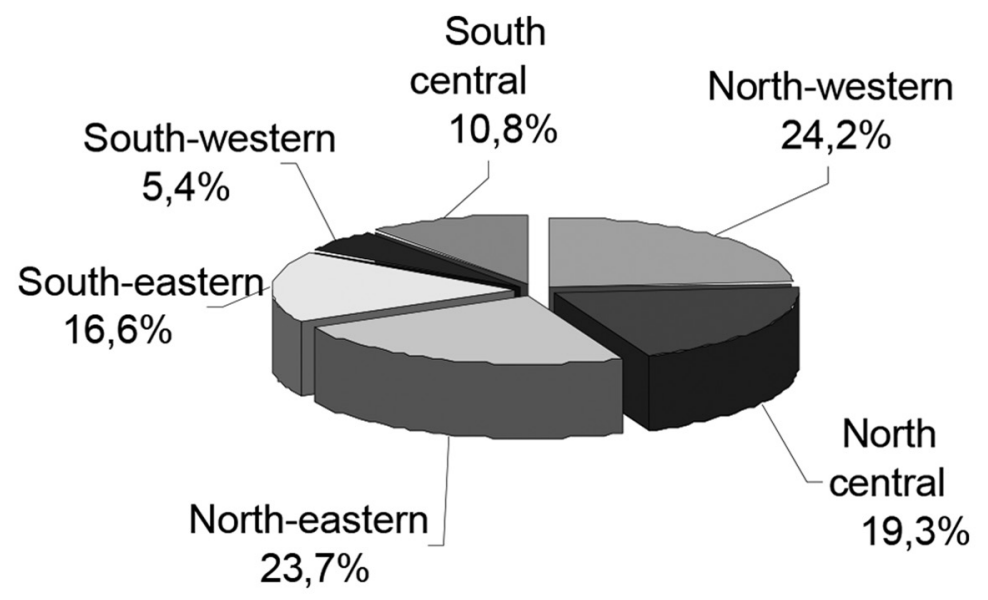

Figure 6: Structure of cereal crop areas by statistical areas of Bulgaria

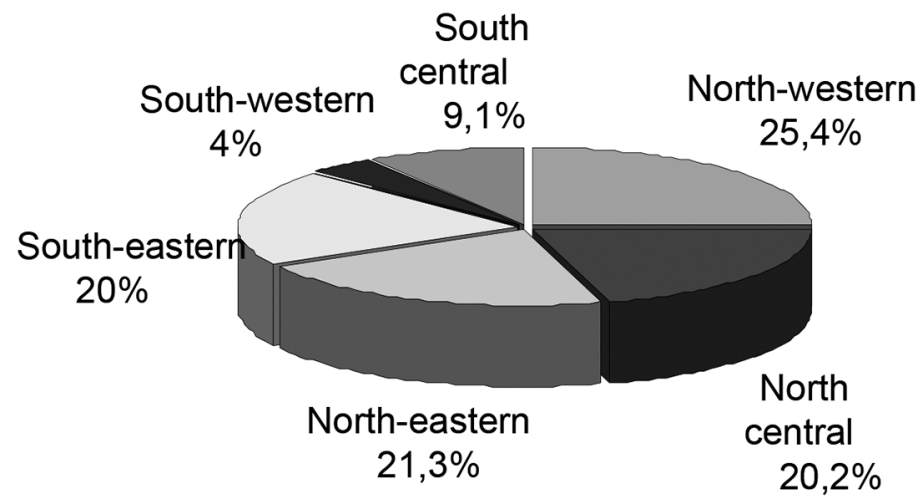

Figure 7: Structure of oleaginous crop areas in Bulgaria by statistical regions

\section{CONCLUSION}

From the generalized characteristics of the state and development of agriculture in Bulgaria by statistical regions, and, in particular, on the territory of the District of Dobrich, as part of the Northeast Planning Region of Bulgaria, the following conclusions could be drawn:

1. According to data released by MAFF, as of 2018, the largest percentage of cultivable agricultural area is concentrated in the Northwest statistical region with a relative share of the land comprising 23,3\%, followed by the Northeast and North Central Region, with 21,6\% and $19,1 \%$, respectively, of the country's total cultivable land;

2. The largest size of cultivable land pertains to the districts of Dobrich and Pleven, comprising $9,6 \%$ and $8,7 \%$, respectively, of the total cultivable area for Bulgaria;

3. Agricultural production within the region of the District of Dobrich has some advantageous characteristic features that set the district apart from the other administrative districts in the country, such as:

3.1. extremely favorable combination of natural and climatic features - a prerequisite for achieving high productivity and quality levels of the regional crop production;

3.2. a high percentage of arable cultivated area, accounting for $71 \%$ of the territory of the district with an average for the country $-58 \%$;

3.3. long-established identification of the agricultural sector as a priority in the structure of the district's regional economy. 


\section{REFERENCES}

[1] Annual Agricultural Report of MAFF, 2016;

[2] Annual Agricultural Report of MAFF, 2017;

[3] Ivanova, D., Report on the Activities of the District Department of "Agriculture" Dobrich during the period of 01. 01. 2017 г. - 30.11. 2017, District Department of "Agriculture", Dobrich, 2017, p. 9;

[4] Nikolov, D., "Concept for Restructuring of Land Relations and Agricultural Production Structures in the District of Dobrich", Dobrich, 2010;

[5] Department of "Agrostatistics", MAFF, Vegetable production in Bulgaria -2015, 2016, 2017 harvest years;

[6] "Agrostatistics", BANCIK, Final results for the employment and land use of the territory of Bulgaria in 2017, pp. 9,10,17;

[7] "Agrostatistics", BANCIK, Final results for the employment and land use of the territory of Bulgaria in 2018, pp. 9,10;

[8] See News, Analysis of the Regional Economy and Opportunities for the Development of the District of Dobrich, October, 2017;

[9] NSI Reference Book for the Republic of Bulgaria, Territorial Units for Statistics- Dobrich, 2018;

[10] Zhekova, R., M. Zlateva, V. Valchinov, Analysis of the Internationalization of Small and Medium-Sized Enterprises in the Northeastern Region of Bulgaria, Projekt: INTRA Interreg Europe, November, 2017;

[11] http://bg.guide-bulgaria.com/ne/dobrich. 